\title{
Tungiasis: presentación familiar de una ectoparasitosis infrecuente
}

\section{Tungiasis: family presentation of an infrequent ectoparasitosis}

Alejandro Leone ${ }^{1}$, Fiorella L. Cardillo Stagno ${ }^{2}$, Cynthia L. Rossi ${ }^{3}$, Valeria Taboada ${ }^{4}$ y Andrea Giuliani ${ }^{5}$

\section{RESUMEN}

La tungiasis es una ectoparasitosis transitoria cuyo agente causal es la hembra grávida de la pulga de la arena Tunga penetrans. Clínicamente, se manifiesta como pápulas blanquecinas con un punto central negro, dolorosas, que suelen afectar los pies. El diagnóstico es clínico y epidemiológico. El tratamiento de elección es la extracción mecánica del parásito, junto con la aplicación de un antibiótico tópico. Presen- tamos 3 casos de tungiasis en una familia que había realizado un viaje reciente a una zona endémica.

Palabras clave: tungiasis, Tunga penetrans, pulga de la arena, ectoparasitosis.

Dermatol. Argent. 2021, 27 (1): 12-15

\section{ABSTRACT}

Tungiasis is an ectoparasitosis caused by the female pregnant, sand flea of the genus Tunga penetrans. Clinically, it presents itself with painful black papular lesions, most of them localized on the feet. Diagnosis of tungiasis is based on the characteristic aspect of the lesions in a patient coming from an endemic area. Surgical removal of the flea and application of a topical antibiotic is the standard treatment. We describe 3 cases of a family that had recently travelled to an endemic zone. Key words: tungiasis, Tunga penetrans, sand flea, ectoparasitosis.

Dermatol. Argent. 2021, 27 (1): 12-15
1 Médico Concurrente de Cuarto Año

2 Médica Concurrente de Cuarto Año

3 Médica Concurrente Quinto Año

4 Médica de Planta

5 Jefa del Servicio

Servicio de Dermatología, Hospital Central de San Isidro Melchor Ángel Posse, Provincia de Buenos Aires, Argentina
Contacto del autor: Cynthia Laura Rossi

E-mail: cynthialrossi@hotmail.com

Fecha de trabajo recibido: 10/10/2020

Fecha de trabajo aceptado: 18/3/2021

Conflicto de interés: los autores declaran que no existe conflicto de interés.

\section{CASOS CLÍNICOS}

Se presentaron a la consulta 3 miembros de una familia, de 58, 60 y 78 ańos, sin antecedentes personales de relevancia, con múltiples lesiones dolorosas en los pies de 20 días de evolución.

Como antecedente epidemiológico, habían viajado a la provincia de Misiones 2 semanas antes del inicio del cuadro clínico. Referían haber viajado en una casa rodante y caminado descalzos.

En el examen físico se destacaban, en los 3 pacientes, múltiples pápulas blanquecinas con un punto negro central y halo eritematoso circundante, dolorosas, en las plantas y el dorso de los dedos de ambos pies 
(Foto 1). En la dermatoscopia, se observó un anillo central marrón oscuro, rodeado de un halo blanquecino hiperqueratósico (Foto 2). Si bien no está indicada la biopsia de piel para su diagnóstico, se tomaron muestras de las lesiones de los 3 pacientes para el estudio histopatológico con fines académicos. Se advirtió la presencia intraepidérmica de la tunga por debajo de la capa córnea (Foto 3) y sus estructuras internas (Foto 4). En uno de los pacientes, se realizó además

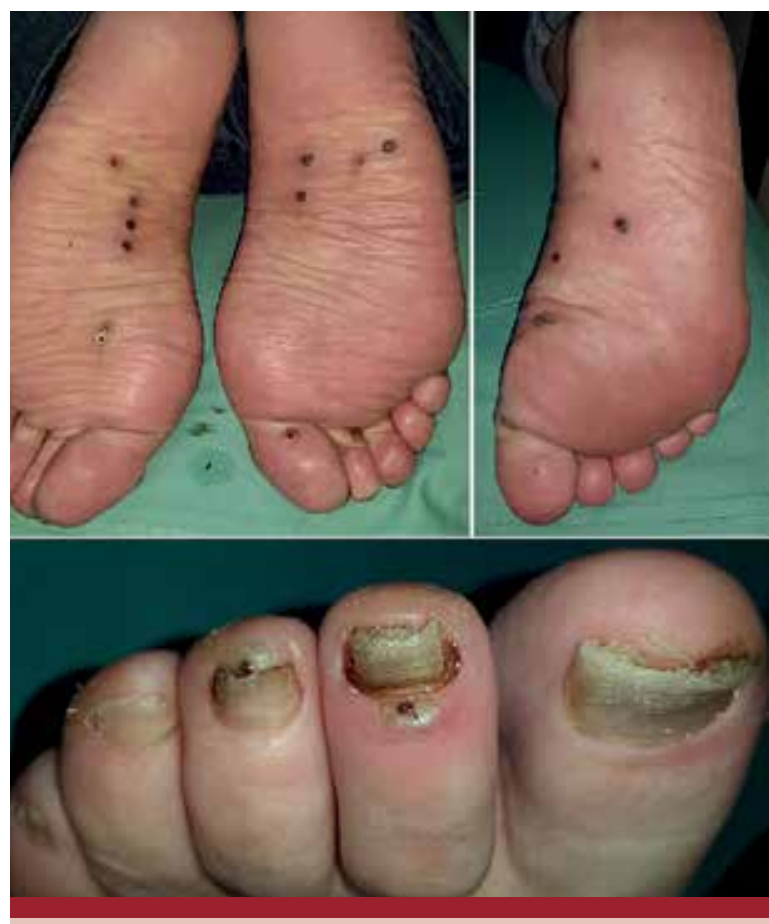

FOTO 1: Múltiples pápulas blanquecinas con un punto negro central y un halo eritematoso en las plantas (en dos pacientes) y en el dorso de los dedos (en un paciente).

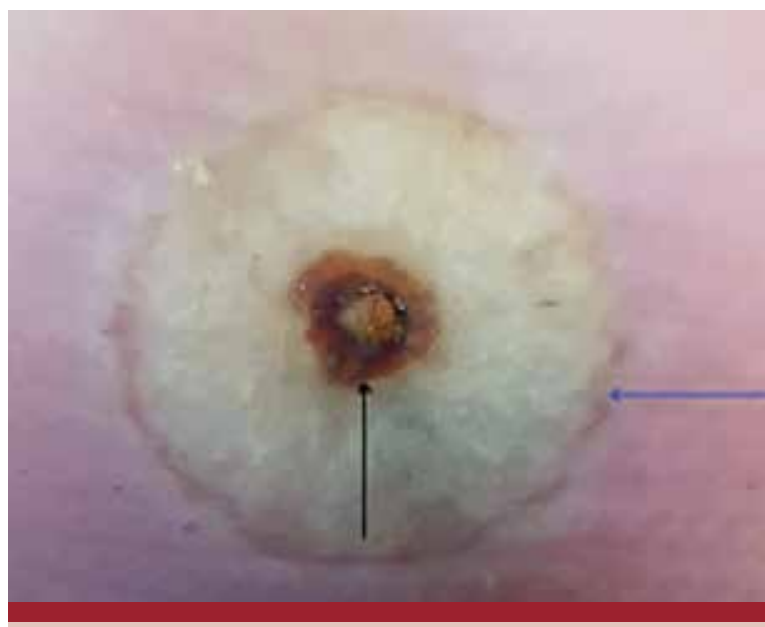

FOTO 2: Imagen dermatoscópica. Se observa un anillo de pigmentación marrón en torno a un poro central (flecha negra), rodeado por una zona blanquecina que se encuentra delimitada por un fino anillo periférico pigmentado (flecha azul). una biopsia escisional que evidenció, en las imágenes macroscópicas, la presencia de huevos en su interior y algunas de las estructuras del parásito (Fotos 5 y 6 ).

Se inició tratamiento con ivermectina por vía oral en dosis única de $200 \mu \mathrm{g} / \mathrm{kg}$, mupirocina crema 2 veces por día durante 10 días y se indicó profilaxis con la vacuna antitetánica.

A los 15 días de iniciado el tratamiento, los pacientes no presentaban dolor y se observaron las lesiones en remisión.

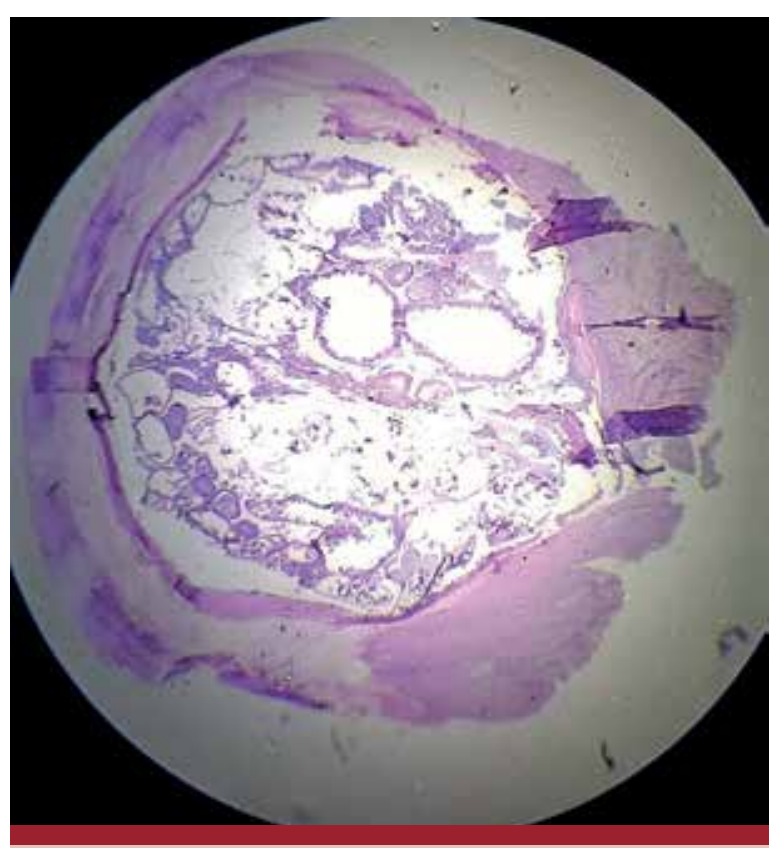

F0T0 3: Imagen panorámica. Biopsia cutánea que muestra un elemento parasitario intraepidérmico (subcórneo) vinculable a Tunga penetrans (HyE, 4X).

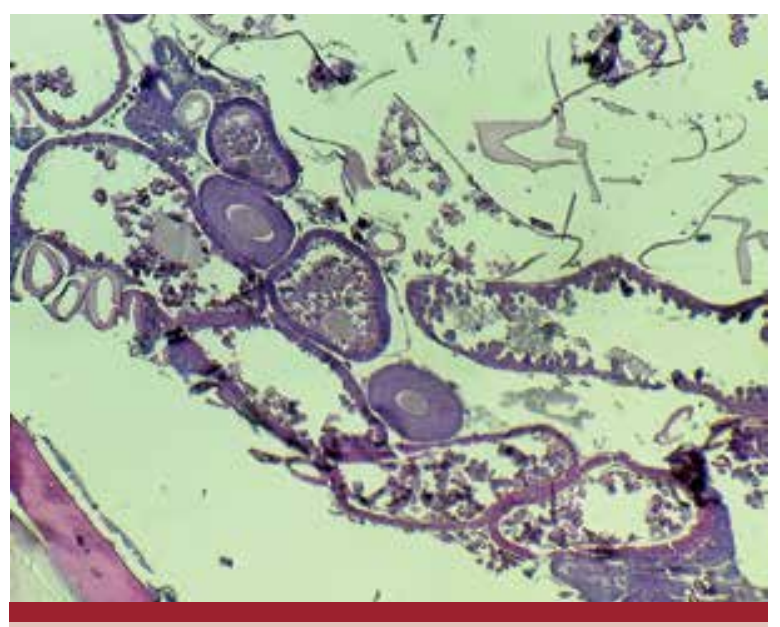

FOT0 4: Imagen histopatológica. Se observan las estructuras internas del parásito, anillos traqueales, tubo digestivo y aparato reproductor con múltiples huevos (HyE, 40X). 


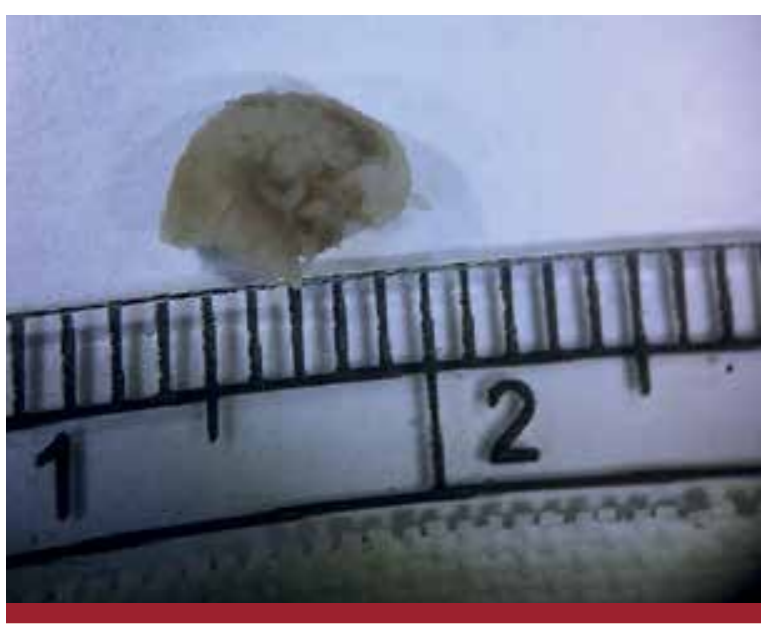

FOT0 5: Imagen macroscópica de la pulga una vez extraída. Corte longitudinal. Se observa la presencia de huevos en la cavidad abdominal

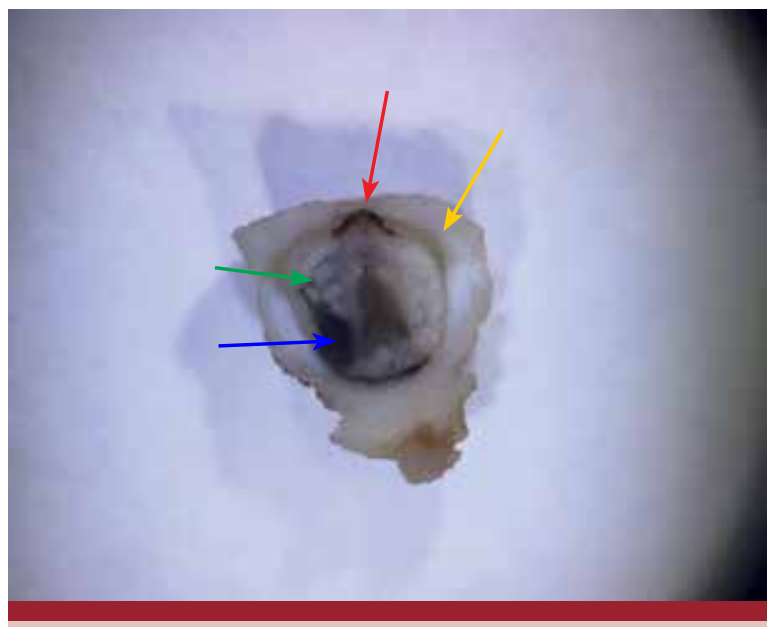

FOTO 6: Imagen macroscópica. Corte longitudinal de la pulga: se observan la cloaca (flecha roja), la piel (flecha amarilla), el abdomen (flecha celeste) y los huevos (flecha verde).

\section{COMENTARIOS}

La tungiasis es una ectoparasitosis transitoria producida por la pulga hematófaga Tunga penetrans. Este parásito recibe diferentes nombres vulgares en distintas regiones geográficas: pique, nigua, pulga de arena, pulga excavadora, bicho do $p e^{1,2}$.

Los estudios epidemiológicos confirman que la pulga prevalece en asentamientos humanos urbanos y rurales de Sudamérica, el Caribe y África subsahariana, en áreas de suelo seco, arenoso y sombreado. En estos lugares es una infestación endémica, lo que representa un problema de salud pública. Las zonas endémicas en nuestro país corresponden a las provincias del Noreste y la Mesopotamia. Como no tiene especificidad de huésped, la tunga puede parasitar tanto al ser humano como a distintos animales, ya sean domésticos o de corral $^{2,3}$.
Dado que muchos casos son adquiridos durante viajes a zonas endémicas e importados en nuestro medio, debemos tenerla presente como diagnóstico diferencial ante lesiones negruzcas en zonas acrales. Algunas de las causas que contribuyen a su desarrollo son el hábito de caminar descalzo en suelos secos y arenosos, la falta de higiene y el contacto con reservorios animales. Prevalece en los niños de hasta 14 años de edad y también en los mayores de 60 años ${ }^{2}$.

La enfermedad se caracteriza por la formación de pápulas con un halo eritematoso que luego de 72 horas se torna blanquecino, con un punto central pardo-negruzco, correspondiente a la zona posterior del abdomen de la pulga. Las áreas de la piel más afectadas son las regiones periungueal y plantar y los talones, como sucedió en los casos relatados. Menos a menudo, puede afectar otras zonas como manos, codos, muslos, párpados superiores y región anogenital ${ }^{3}$. Puede cursar con prurito o dolor leve, pero también ocasionar un dolor intenso e imposibilidad para la deambulación ${ }^{4}$. En otras ocasiones, los pacientes solo refieren una sensación de cuerpo extraño. Se describieron variantes clínicas menos frecuentes como ampollar, pustulosa, costrosa, ulcerada y verrugosa ${ }^{5}$.

Las complicaciones son sobreinfección bacteriana, linfangitis e infartos ganglionares, o tétanos en los pacientes no vacunados. En los casos graves, la falta de tolerancia al dolor puede llevar a la amputación de los dedos. Existen casos de infestación con hasta 30 pulgas en un área anatómica, lo que conduce a una marcada inflamación y al desarrollo de discapacidades, con alteraciones en la marcha ${ }^{5,6}$.

El diagnóstico de tungiasis es clínico, con la visualización de las típicas lesiones en un paciente y epidemiológico, con el antecedente de haber estado en un área endémica. La dermatoscopia facilita el diagnóstico, ya que permite ver el exoesqueleto oscuro del insecto y múltiples huevos en el nódulo hiperqueratósico ${ }^{7,8}$.

En las tungiasis atípicas, puede estar indicada la biopsia de las lesiones con aspecto seudoepiteliomatoso en sitios ectópicos. En los pacientes presentados se decidió realizarla con fines académicos. El estudio histopatológico suele mostrar la presencia del parásito a nivel intraepidérmico (subcórneo), su exoesqueleto y sus huevos ${ }^{9,10}$.

Como diagnósticos diferenciales se plantean: escabiosis, piodermitis o abscesos, larva migrans cutánea, miasis, verrugas, melanoma acral, reacción a un cuerpo extraño, entre otros 9 .

El tratamiento puede ser local o sistémico. El primero comprende la extracción de la pulga y sus huevos con una aguja estéril. Se debe limpiar la cavidad 
cautelosamente con un antiséptico y luego aplicar un antibiótico local en crema. La extracción del parásito debe ser completa, ya que si quedan restos en el huésped se puede generar una respuesta inflamatoria local importante. En caso de sobreinfección bacteriana, se debe administrar un antibiótico por vía oral. Ante múltiples lesiones, se recomienda utilizar ivermectina por vía oral en dosis única de $200 \mu \mathrm{g} / \mathrm{kg}$, como en los pacientes comunicados ${ }^{10}$.

Se debe aplicar la vacuna antitetánica a los pacientes vacunados hace más de 5 años o que hasta el momento no la hayan recibido ${ }^{10,11}$.

La prevención es fundamental, por lo que se recomienda a los viajeros a zonas endémicas el uso de

\section{BIBLIOGRAFÍA}

1. Hoon K, Fernández $M$, Buján $M$, Cervini A. Tungiasis. Presentación de un caso clínico. Arch Argent Pediatr 2011;109:e82-e84/e82.

2. Verdi M, Benavente D, Gentile J, Omaña S, et ál. Tungiasis. Rev Argent Dermatol 2008;89:226-233.

3. Connett J, George R. Vacation dermatoses. J Am Acad Dermatol 2014;70:961-963.

4. Cagnon GV, Carvalho dos Santos D, Miot HA. Tungiasis. JAMA Dermatol 2019;155:1181.

5. Meneses Díaz E, Pavón E, Bagalá ME, Cortés L, et ál. Tungiasis, un souvenir del viajero. Dermatol Argent 2020;26:68-72.

6. Garlatti ML, Vacas AS, Enz P, De Luca D, et ál. Serie Parasitosis en Dermatología. Tungiasis. Rev Hosp Ital B Aires 2017;37:112-115.

7. Sendagorta E, Vidaurrázaga C, Mulekyo R. Placa hiperpigmentada en el pie de un paciente keniata. Actas Dermosifiliogr 2012;103:633-634. calzado cerrado, evitar sentarse o recostarse en sitios en los que habita la pulga como suelos secos y arenosos, y realizar un autoexamen para la detección de lesiones ${ }^{12}$.

Para concluir, queremos destacar la importancia de que los médicos estén familiarizados con esta enfermedad, ya que al no ser frecuente en nuestro medio, puede ser subdiagnosticada. Si bien rara vez se observan complicaciones, cuando hay múltiples lesiones, como en los casos presentados, estas actúan como puerta de entrada a los microorganismos y el riesgo de infección es mayor. Por lo tanto, saber reconocerla nos da la oportunidad de instaurar un tratamiento precoz y evitar las complicaciones.

8. Santos RP, Resende C, Duarte M, Brito C. Tungiasis: a poorlyknown diagnosis in Europe. Two paradigmatic cases from Portugal. Acta Dermatovenerol APA 2017;26:115-117.

9. Leiro V, Novac V, Olivares L, Maronna E. Tungiasis inusual: forma clínica ampollar. Dermatol Argent 2010;16:344-348.

10. Ferreyra V, Martinetti C, Natinzon R, Rojas G, et ál. Tungiasis: Reporte de un caso clínico con evolución inesperada. Fenómeno isotópico. Rev Argent Dermatol 2019;100:36-48.

11. Fich F, Del Barrio-Díaz P, Kam S, Celle VM, et ál.Tungiasis, una enfermedad tropical emergente en Chile. Comunicación de tres casos clínicos importados. Rev Chil Infectol 2013;30:676-679.

12. González A, de Villalobos C, Ranalletta MA, Coscarón M. Aspectos adaptativos y biológicos de Tunga penetrans (Linné 1758). Epidemiología en comunidades aborígenes del norte argentino. Arch Argent Dermatol 2004;54:119-123. 